\title{
Phenolics, antioxidative activity and characterization of anthocyanins in berries of blackcurrant interspecific hybrids*
}

\author{
Nijolè Anisimovienè ${ }^{1 凶}$, Jurga Jankauskienè ${ }^{1}$, Milda Jodinskienè ${ }^{1}, V^{2}$ idmantas Bendokas ${ }^{2 凶}$, \\ Vidmantas Stanys² and Tadeušas Šikšnianas²
}

${ }^{1}$ Laboratory of Plant Physiology, Institute of Botany of Nature Research Centre, Vilnius, Lithuania; ${ }^{2}$ Department of Orchard Plant Genetics and Biotechnology, Institute of Horticulture, Lithuanian Research Centre for Agriculture and Forestry, Babtai, Kaunas distr., Lithuania

\begin{abstract}
The interest in phenols and anthocyanins has increased due to their antioxidant properties and to their potential usage as dietary antioxidants in human nutrition. Total phenols and anthocyanin content, composition and stability in berry extracts of blackcurrant interspecific hybrids, and antioxidative activity of extracts was evaluated. Berries of interspecific hybrids accumulated 530 to $614 \mathrm{mg} 100 \mathrm{~g}^{-1} \mathrm{FW}$ of total phenolic compounds, while $621 \mathrm{mg} 100 \mathrm{~g}^{-1} \mathrm{FW}$ of phenolics was established in berries of control Ribes nigrum cultivar 'Ben Tirran'. 'Ben Tirran' berries accumulated $444 \mathrm{mg} 100 \mathrm{~g}^{-1} \mathrm{FW}$ of anthocyanins and higher amount was identified in berries of interspecific hybrids No. 11-13 (R. nigrum $\times R$. petraeum) and No. 57 (R. nigrum $\times R$. aureum), 522 and 498 mg100 $\mathrm{g}^{-1}$ FW respectively. Berry extracts of hybrid No. 11-13 distinguished by the highest antioxidative activity $(80 \%)$ and it was higher than antioxidant activity of 'Ben Tirran' (70\%). Antioxidative activity of all tested berry extracts $(70-80 \%)$ was twice higher compared to synthetic antioxidant BHT (39\%). However correlation between phenolics or total anthocyanin content and antioxidative activity degree was not established. Amount of cyanidin 3-O-glucoside and cyanidin 3-O-rutinoside in berries of hybrids No. 57, No. 11-13 and No. 8 ((R. nigrum $\times R$. americanum $) \times(R$. nigrum $\times R$. americanum $))$ was higher than in berries of 'Ben Tirran'. It was established that cyanidins are more stable anthocyanins in all studied temperature and irradiation conditions. Therefore interspecific hybrids No. 57 and No. 11-13 were the most agronomically valuable hybrids.
\end{abstract}

Key words: anthocyanins, antioxidative activity, interspecific hybrids, phenolics, stability

Received: 14 October, 2013; revised: 06 December, 2013; accepted: 06 December, 2013; available on-line: 29 December, 2013

\section{INTRODUCTION}

Search of bioactive plant materials important to human health is one of problems in biomedical research (Pourmorad et al., 2006; Pascual-Teresa \& Sanches-Ballesta, 2008; Borges et al., 2010; Bunea et al., 2011). Bioactive substances like anthocyanins, other phenolic compounds, including tannins, proanthocyanidins and phenolic acids derived from berries have received considerable interest (Moyer et al., 2002; Horbowicz et al., 2008; Arnnok et al., 2012; Tsuda, 2012). The interest in anthocyanins has increased due to their antioxidant properties and to their potential usage as dietary antioxidants in human nutrition (Pascual-Teresa \& Sanches-Ballesta, 2008; Lugasi et al., 2011). The most important role of anthocyanins is the antioxidant activity, which includes protection against DNA damage, free radical scavenging, coursing depletion of immune system antioxidants, change in gene expression and induce formation the abnormal proteins, involved in many health disorders (Pourmorad et al., 2006; Oancea \& Oprean, 2011). It is known, that these compounds are being able to capture reactive oxygen species, such as superoxide radical $-\mathrm{O}_{2}^{-}$; hydroxyl radical - $\mathrm{HO}^{-}$, hydrogen peroxide $-\mathrm{H}_{2} \mathrm{O}_{2}$ or singlet oxygen $-{ }^{1} \mathrm{O}_{2}$, can delay the initiation or propagation of oxidatative chain reactions, inhibits the oxidation (Javanmardi et al., 2003; Denev et al., 2012). Numerous publications are presented in which the antioxidative activity of anthocyanins extracted from berries or fruits is indicated (Pantelidis et al., 2007; Horbowicz et al., 2008; Djordjević et al., 2010). To date the potential effect of anthocyanins, other phenolic compounds in reducing the incidence of cardiovascular disease prevention, cancer, diabetes, hyperlipidemias, possessing anti-microbial, anti-inflammatory and anti-carcinogenic activity, obesity control, and other chronic diseases are indicated (Pascual-Teresa \& Sanches-Ballesta, 2008; Liegiūte et al., 2009; Liobikas et al., 2009; Shipp \& Abdel-Aal, 2010; Oancea \& Oprean, 2011; Tsuda, 2012).

More than 635 natural anthocyanins were identified, they are constituted from anthocyanidins which are differently glycosylated and acylated (He \& Giusti, 2010), although the relationship between their function and structure are disputable and remains under consideration. Anthocyanins lacking the O-diphenyl structure in the B ring (malvidin, pelargonidin, petunidind and penonidin) have a lower DPPH radical scavenging efficiency compared to cyanidin and delphinidin. Position of hydroxylation and methylation in the B ring affects the stability, reactivity and antioxidant capacity of the anthocyanins expressed as DPPH test; as weaker or stronger as free radicals scavengers are their glucosides or rutinosides (Shipp \& Abdel-Ala, 2010). The composition of anthocyanins in different plant species berries or fruits is not enough investigated and we have knowledge gaps whether composition of anthocyanins and/or which alone anthocyanin have the most significant impact in their antioxidant capacity.

e-mail: N. Anisimovienė: nijole.anisimoviene@botanika.lt; V. Bendokas: v.bendokas@lsdi.lt

*Presented at the 5th Central European Congress of Life Sciences „EUROBIOTECH 2013", Kraków, Poland. 
Content, composition and antioxidant activity of anthocyanins and other phenolic compounds in berries depends not only on genotype, but also on environmental factors (Blando et al., 2004; Pantelidis et al., 2007; Horbowicz et al., 2008). Therefore anthocyanin content, composition and activity in plants, grown in different countries should be studied. The growing interest of antioxidant influence on human health (Guerrero et al., 2010) has triggered the identification of new producers of phenolics compounds and anthocyanins, which distinguishes in their antioxidative activity. The berries of Ribes genus are considered to be rich in anthocyanins and total phenolics in various countries (Slimestad \& Solheim, 2002; Rubinskienè et al., 2005; Horbowicz et al., 2008), breeding programs were aimed to increase berry nutritional value.

The aim of our study was to analyse total phenols and to evaluate anthocyanin content, composition and stability in berry extracts of blackcurrant interspecific hybrids, to evaluate antioxidative activity of extracts and to identify perspective hybrids - a new sources of anthocyanins and phenols with high antioxidative capacity.

\section{MATERIALS AND METHODS}

Plant material. Anthocyanins, total phenols and antioxidative activity of berry extracts of blackcurrant (Ribes nigrum) 'Ben Tirran' and complex interspecific hybrids of blackcurrant with american currant ( $R$. americanum), golden currant ( $R$. aureum), gooseberry ( $R$. uva-crispa) and red currant $(R$. petraeum): No. 6 (R. nigrum $\times R$. americanum $) \times$ $[(\mathrm{R}$. nigrum $\times \mathrm{R}$. aureum $) \times \mathrm{R}$. uva-crispa $]$, No. 8 ( $\mathrm{R}$. nigrum $\times R$. americanum $) \times(\mathrm{R}$. nigrum $\times \mathrm{R}$. americanum $)$, No. $11-$ 13 R. nigrum $\times$ R. petraeum, No. 57 R. nigrum $\times$ R. aureum were studied. Berries were collected at technical maturity phase, immediately frozen and stored at $-70^{\circ} \mathrm{C}$ until analysis.

Extraction of phenolic compounds and anthocyanins. Anthocyanins and other phenolics were extracted from frozen berries ground to a fine powder using $90 \%$ aqueous methanol, acidified with $\mathrm{HCl}$ to $0.1 \mathrm{~N}$ at ratio $1: 20 \mathrm{~g} / \mathrm{mg}$ and stored for $16 \mathrm{~h}$ at $4^{\circ} \mathrm{C}$ in the dark (Anisimoviene et al., 2009; Arrnok et al., 2012). Reagents were purchased from Sigma-Aldrich. The material was shaken twice for $30 \mathrm{~min}$ at $4^{\circ} \mathrm{C}$ in the dark during the extraction procedure. The extract was filtrated through membrane filters $(0.2-\mu \mathrm{m}$ pore diameter, Whatman) residues were washed until solvent became colourless.

The obtained methanol extracts were used for determination of anthocyanins and total phenolics and for establishment of antioxidative activity. Later extracts were vacuum dried, using an IKA RV-10 water pump (Germany) at $40^{\circ} \mathrm{C}$. Samples were stored at $-70^{\circ} \mathrm{C}$ until analysis of anthocyanin composition using high performance liquid chromatography method (HPLC) and for study of stability of antioxidative activity.

Determination of total anthocyanins. The anthocyanins content was determined using a spectrophotometric differential pH method (Wrolstad et al., 2005; Horbowicz et al., 2008). Absorbance of the extracts was measured at 520 and $700 \mathrm{~nm}$, using a UV-VIS spectrophotometer (Specord 210 PLUS, Analytik Jena AG, Jena, Germany). Buffers: pH 1.0 (hydrochloric acid-potassium chloride $0.025 \mathrm{M}$ ) and $\mathrm{pH} 4.5$ (hydrochloric acid-sodium acetate $0.4 \mathrm{M}$ ). Exposition time was $30 \mathrm{~min}$, at $25^{\circ} \mathrm{C}$ in dark. Anthocyanins content was calculated using a molar extinction coefficient of cyanidin-3-glucoside chloride (c3g). Results were expressed as cyanidin-3-glucoside equivalents mg $100 \mathrm{~g}^{-1}$ fresh weight (FW). Reagents were purchased from Sigma-Aldrich.

Determination of phenolic compounds. Total phenolics content in crude methanol extracts was determined by Folin-Ciocalteu method Slinkard and Sigleton (1977) as referred by (Pantelidis et al., 2007). Folin-Cioceltau's reagent (Fluka) was diluted with distillated water $\left(1 / 10, \mathrm{v} / \mathrm{v}\right.$ ) and $7.5 \%$ aqueous $\mathrm{Na}_{2} \mathrm{CO}_{3}$ (both from Sigma-Aldrich) were used for measurement. Exposition time was $30 \mathrm{~min}$, at $25^{\circ} \mathrm{C}$ temp in dark. Absorbance of samples was measured at $765 \mathrm{~nm}$, using spectrophotometer (Specord 210 PLUS, Germany). The gallic acid (Sigma-Aldrich) was used as a standard. Phenolic compound content was expressed as $\mathrm{mg} 100 \mathrm{~g}^{-1} \mathrm{FW}$.

Determination of antioxidant activity. The antioxidant activity (capacity) of methanol extracts derived from various berries was determined spectrophotometrically according a free radical scavenging activity, using the 2,2-diphenyl-1-picrylhydrazyl (DPPH) method (Anisimoviene et al., 2009; Viskelis et al., 2010; Bunea et al., 2011; Hassanpour et al., 2011). DPPH was purchased from Sigma-Aldrich. Fifty microliters of methanol extracts derived from various berries (concentrations 13-16 $\mathrm{mg} \mathrm{mL}-1)$ were mixed with $1.0 \mathrm{~mL}^{-1}$ of $6 \times 10^{-5} \mathrm{~mol} \mathrm{~L}^{-1}$ of freshly prepared DPPH. Mixtures were kept in dark at $25^{\circ} \mathrm{C}$ for $30 \mathrm{~min}$. The absorbance was measured at $515 \mathrm{~nm}$, using spectrophotometer (Specord 210 PLUS, Analytik Jena AG, Jena, Germany). The antioxidative activity — inhibition of DPPH radical (\%) was evaluated according the absorbance of the blank solution and absorbance value of sample solution and expressed in percents $(\%)$. The antioxidative activity $(\%)$ of tested materials was compared to antioxidant activity of synthetic inhibitor 2,6-di-tret-butyl-4-methyl-phenol (BHT) (Sigma-Aldrich).

Determination of anthocyanins composition. The composition of anthocyanins in prepared extracts was investigated using HPLC (Durst \& Wrolstad, 2001; Liobikas et al., 2009). Anthocyanin analysis was performed using Agilent 1200 HPLC system with DAD detector (Agilent, Germany); reverse phase XBridge Shield RP18 (Waters, UK) analytical column $(3.0 \times 150 \mathrm{~mm}$, particle size $3.5 \mu \mathrm{m})$ was used. The mobile phase consisted of $10 \%$ acetic acid and 1\% phosphoric acid (solvent $\mathrm{A}$ ) and $100 \%$ acetonitrile (solvent B), HPLC ultra gradient grade reagents were purchased from Sigma-Aldrich. The elution conditions were as follows: isocratic elution $0 \% \mathrm{~B}$, 0-12 min; linear gradient from $0 \% \mathrm{~B}$ to $7 \% \mathrm{~B}, 12-15$ $\mathrm{min}$; to $45 \% \mathrm{~B}, 17 \mathrm{~min}$; to $100 \% \mathrm{~B}, 20 \mathrm{~min}$, flow rate $0.7 \mathrm{ml} \mathrm{min}-1$. Detector wavelength of $520 \mathrm{~nm}$ was used. Anthocyanin standards: cyanidin 3-O-glucoside (c3g), cyanidin 3-O-rutinoside (c3r), delphinidin 3-O-rutinoside (d3r), delphinidin 3-O-glucoside (d3g), pelargonidin 3-O-glucoside (pel3g), peonidin 3-O-rutinoside (peo3r) and malvidin 3-O-glucoside (m3g) (Extrasynthese, France; Polyphenols Laboratories AS, Norway) were used for identification and quantification of individual anthocyanins.

Evaluation of anthocyanin stability in berry extracts. Stability of anthocyanins in berry extracts of interspecific hybrid No. 57 was evaluated at different irradiance and temperature conditions. Storing conditions: $+23 \pm 2^{\circ} \mathrm{C}$ with $50-150 \mu \mathrm{mol} \mathrm{m}{ }^{-2} \mathrm{~s}^{-1}$ photosynthetic photon flux density; $+23 \pm 2^{\circ} \mathrm{C}$ in dark and $+4 \pm 1^{\circ} \mathrm{C}$ in dark. Anthocyanin content and composition was evaluated after 2, 7, 14, 28, 56 and 84 days of storage using HPLC.

Statistical analysis. Average data and \pm S.E. are presented for 5 repetitions. The data were computed using 


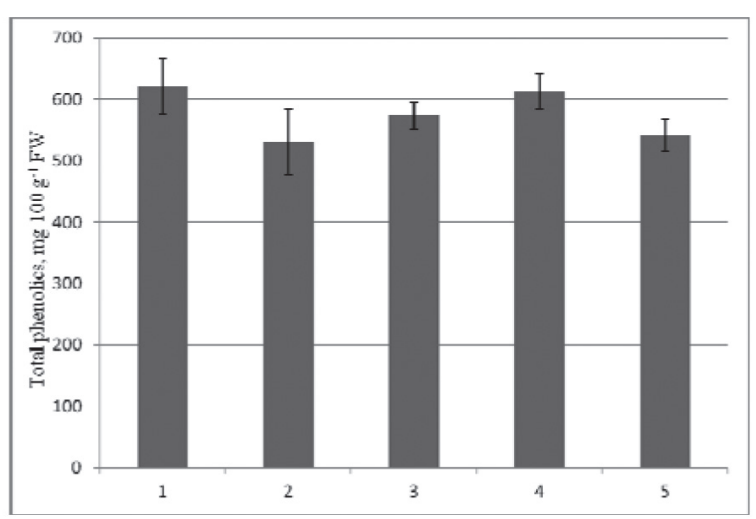

Figure 1. Amount of phenolic compounds in berries of 'Ben Tirran' and interspecific Ribes hybrids.

1 - R. nigrum 'Ben Tirran', 2 - No. 6 (R. nigrum $\times$ R. americanum) $\times[($ R. nigrum $\times R$. aureum $) \times R$. uva-crispa $], 3-$ No. 8 ( $R$. nigrum $\times R$. americanum $) \times(R$. nigrum $\times R$. americanum $), 4-$ No. 11-13 $R$. nigrum $\times R$. petraeum, $5-$ No. $57 R$. nigrum $\times R$. aureum. Mean \pm S.E. are presented, $n=5$.

the Microsoft Excel Descriptive Statistics program at the 95\% confidence level.

\section{RESULTS AND DISCUSSION}

\section{Content of phenolics in berries of interspecific blackcurrant hybrids}

The highest amount of total phenolic compounds (above $600 \mathrm{mg} 100 \mathrm{~g}^{-1} \mathrm{FW}$ ) was established in berries of 'Ben Tirran' and hybrid No. 11-13 (R. nigrum $\times$ R. petraeum) (Fig. 1). Berries of interspecific Ribes hybrids accumulated less phenolics, than control variety 'Ben Tirran'. According other studies, higher phenolics content is characteristic to blackcurrant compared to gooseberries and redcurrants (Moyer et al., 2002; Horbowicz et al., 2008; Pinto et al., 2010). Therefore lower amount of phenolics in interspecific hybrids was due blackcurrant hybridisation with these species.

\section{Content of anthocyanins in berries of interspecific blackcurrant hybrids}

The blackcurrants are recognized as a good source of anthocyanins and are valued for their health benefits. The anthocyanin content established in blackcurrant berries ranges in different studies from 130-400 mg $100 \mathrm{~g}^{-1}$ FW (Horbowicz et al., 2008); 280-675 mg $100 \mathrm{~g}^{-1} \mathrm{FW}$ (Hellström et al., 2010); 161-284 mg $100 \mathrm{~g}^{-1}$ FW (Nour et al., 2011). Anthocyanins content in 33 several R. nigrum cultivars and hybrids ranged from 128 to $411 \mathrm{mg}$ $100 \mathrm{~g}^{-1}$ FW (Moyer et al., 2002). Different anthocyanin amount was established in berries of various Ribes species and interspecific hybrids (Fig. 2).

Anthocyanin amount in blackcurrant 'Ben Tirran' was high (443.9 mg $100 \mathrm{~g}^{-1} \mathrm{FW}$ ), similar results were obtained earlier (Anisimoviene et al., 2009), however the highest amount of anthocyanins was identified in berries of hybrid No. 11-13 (R. nigrum $\times$ R. petraeum) -522.8 mg $100 \mathrm{~g}^{-1} \mathrm{FW}$. Complex hybrid No. $6((\mathrm{R}$. nigrum $\times$ $\mathrm{R}$. americanum $) \times[(\mathrm{R}$. nigrum $\times \mathrm{R}$. aureum $) \times \mathrm{R}$. uva-cris$p a])$ and No. $8((R$. nigrum $\times R$. americanum $) \times(R$. nigrum $\times \mathrm{R}$. americanum) had the lowest amount of anthocyanins in berries between studied hybrids $378.9 \mathrm{mg} 100$ $\mathrm{g}^{-1} \mathrm{FW}$ and $423.7 \mathrm{mg} 100 \mathrm{~g}^{-1} \mathrm{FW}$ respectively, however

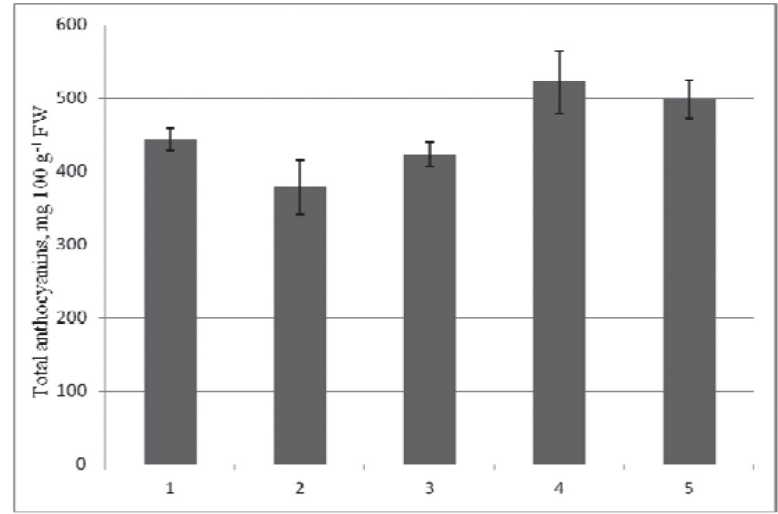

Figure 2. Anthocyanin amount in berries of 'Ben Tirran' and interspecific Ribes hybrids.

1 - R. nigrum 'Ben Tirran', $2-$ No. 6 (R. nigrum $\times R$. americanum) $\times[(\mathrm{R}$. nigrum $\times R$. aureum $) \times R$. uva-crispa $], 3-$ No. 8 ( $R$. nigrum $\times R$. americanum $) \times(R$. nigrum $\times R$. americanum $), 4-$ No. 11-13 $R$. nigrum $\times R$. petraeum, $5-$ No. $57 R$. nigrum $\times R$. aureum. Mean \pm S.E. are presented, $n=5$.

that amount was above average found in other European countries (Horbowicz et al., 2008; Nour et al., 2011). Our results show that blackcurrant berries in Lithuania are rich sources of anthocyanins.

\section{Antioxidative activity of berry extracts of interspecific blackcurrant hybrids}

One of the most important roles of anthocyanins is their antioxidative activity - capability to scavenge the free radicals (Onacea \& Optean, 2011). Antioxidative activity showed no significant variations between tested blackcurrants and it ranged from 69\% to $80 \%$ (Fig. 3). Besides that, andioxidative activity of all tested extracts was twice higher compared to synthetic antioxidant butylated hydroxytoluene (BHT). Also, antioxidative activity of Ribes berry extracts was higher compared to blueberries, elderberries (Anisimovienè et al., 2009).

The highest antioxidative activity was identified in berry extracts of hybrid No. $11-13$ ( $R$. nigrum $\times R$. petraeum) and No. $6((\mathrm{R}$. nigrum $\times \mathrm{R}$. americanum $) \times[(\mathrm{R}$. nigrum $\times$ $R$. aureum $) \times R$. uva-crispa]) and it was higher than antioxidant activity of a control blackcurrant cultivar 'Ben

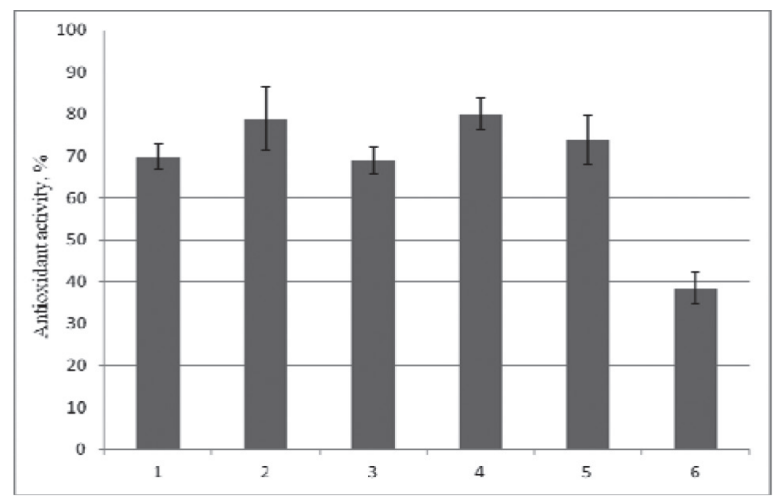

Figure 3. Antioxidant activity of 'Ben Tirran' and interspecific Ribes hybrids berry extracts.

$1-R$. nigrum 'Ben Tirran', $2-$ No. 6 (R. nigrum $\times$ R. americanum) $\times[($ R. nigrum $\times R$. aureum $) \times R$. uva-crispa $], 3-$ No. $8(R$. nigrum $\times$ $R$. americanum $) \times(R$. nigrum $\times R$. americanum $), 4-$ No. 11-13 $R$. nigrum $\times R$. petraeum, 5 - No. 57 R. nigrum $\times$ R. aureum, 6 - synthetic antioxidant butylated hydroxytoluene (BHT). Mean \pm S.E. are presented, $\mathrm{n}=5$. 
Table 1. Anthocyanin composition in berry extracts of 'Ben Tirran' and interspecific Ribes hybrids.

$1, R$. nigrum 'Ben Tirran'; 2, No. 6 (R. nigrum $\times R$. americanum) $\times[($ R. nigrum $\times R$. aureum $) \times R$. uva-crispa], 3, No. $8(R$. nigrum $\times R$. americanum $) \times(R$. nigrum $\times R$. americanum); 4, No. 11-13 R. nigrum $\times R$. petraeum; 5, No. 57 R. nigrum $\times R$. aureum. d3g - delphinidin 3-O-glucoside, d3r - delphinidin 3-O-rutinoside, c3g - cyanidin 3-O-glucoside, c3r - cyanidin 3-O-rutinoside, pel3g - pelargonidin 3-O-glucoside, $\mathrm{m} 3 \mathrm{~g}$ - malvidin 3-O-glucoside, $\mathrm{x}$ - unidentified anthocyanins.

\begin{tabular}{|c|c|c|c|c|c|c|c|c|c|}
\hline Cultivar, hybrid & d3g & $d 3 r$ & $c 3 g$ & $\mathrm{c} 3 \mathrm{r}$ & pel3g & peo3r & peo3g & $\mathrm{m} 3 \mathrm{~g}$ & $x$ \\
\hline 1. ('Ben Tirran') & $\begin{array}{l}78.56 \\
\pm 2.55\end{array}$ & $\begin{array}{l}200.39 \\
\pm 6.80\end{array}$ & $\begin{array}{l}14.57 \\
\pm 0.52\end{array}$ & $\begin{array}{l}120.90 \\
\pm 4.75\end{array}$ & $\begin{array}{l}0.64 \\
\pm 0.03\end{array}$ & - & $\begin{array}{l}2.27 \\
\pm 0.16\end{array}$ & $\begin{array}{l}2.17 \\
\pm 0.16\end{array}$ & $\begin{array}{l}24.92 \\
\pm 0.67\end{array}$ \\
\hline 2. & $\begin{array}{l}77.07 \\
\pm 6.56\end{array}$ & $\begin{array}{l}149.76 \\
\mathbf{\pm 2 6 . 8 8}\end{array}$ & $\begin{array}{l}28.01 \\
\pm 5.51\end{array}$ & $\begin{array}{l}111.06 \\
\pm 17.17\end{array}$ & $\begin{array}{l}5.32 \\
\mathbf{\pm 0 . 2 3}\end{array}$ & - & - & $\begin{array}{l}3.86 \\
\pm 0.23\end{array}$ & $\begin{array}{l}3.77 \\
\pm 1.37\end{array}$ \\
\hline 3. & $\begin{array}{l}116.03 \\
\pm 7.94\end{array}$ & $\begin{array}{l}120.99 \\
\pm 14.33\end{array}$ & $\begin{array}{l}49.69 \\
\pm 2.24\end{array}$ & $\begin{array}{l}110.44 \\
\pm 11.40\end{array}$ & $\begin{array}{l}5.04 \\
\pm 0.27\end{array}$ & - & - & $\begin{array}{l}5.25 \\
\pm \mathbf{0 . 2 4}\end{array}$ & $\begin{array}{l}16.22 \\
\mathbf{+ 1 . 8 4}\end{array}$ \\
\hline 4. & $\begin{array}{l}70.71 \\
\pm 6.24\end{array}$ & $\begin{array}{l}262.53 \\
\pm 7.92\end{array}$ & $\begin{array}{l}25.03 \\
\mathbf{\pm 1 . 7 7}\end{array}$ & $\begin{array}{l}146.04 \\
\mathbf{\pm 8 . 0 6}\end{array}$ & $\begin{array}{l}4.26 \\
\mathbf{\pm 0 . 1 5}\end{array}$ & $\begin{array}{l}0.97 \\
\pm 0.16\end{array}$ & - & $\begin{array}{l}1.74 \\
\mathbf{\pm 0 . 1 3}\end{array}$ & $\begin{array}{l}11.47 \\
\mathbf{0 0 . 7 4}\end{array}$ \\
\hline 5. & $\begin{array}{l}103.44 \\
\pm 3.06\end{array}$ & $\begin{array}{l}186.76 \\
\mathbf{\pm 5 8 . 4 1}\end{array}$ & $\begin{array}{l}49.89 \\
\pm 29.02\end{array}$ & $\begin{array}{l}150.23 \\
\mathbf{\pm 3 2 . 0 5}\end{array}$ & $\begin{array}{l}1.45 \\
\mathbf{\pm 0 . 2 7}\end{array}$ & - & - & $\begin{array}{l}1.39 \\
\mathbf{\pm 0 . 3 1}\end{array}$ & $\begin{array}{l}5.63 \\
\pm 1.53\end{array}$ \\
\hline
\end{tabular}

Mean \pm S.E. are presented, $\mathrm{n}=5$.

Tirran' (Fig. 3). However, direct correlation between anthocyanin or phenolics amount and degree of antioxidative activity was not established. It is possible to assume that if the other free radicals such as: - cation 2,2-azinobis-(3-ethylbenzothiazoline-6-sulphonate) $\left(\mathrm{ABTS}^{\bullet+}\right)$, cation from N,N -dimethyl-p-phenylenediamine (DMPD ${ }^{+}$), oxygen-radical absorbance capacity (ORAC) or ferric reducing antioxidant power (FRAP) (Sánchez-Moreno, 2002; Moyer et al., 2002; Pantelidis et al., 2007; Bunea et al., 2011) had been chose, the results could have shown some differences in comparison to DPPH assay. But this method was chosen not only as the most useful or accessible for antioxidative axtivity determination, but also in order to compare the antioxidative activity of hybrids, namely, with the activity of other blackcurrant cultivars growing in Lithuania, tested by DPPH assay (Anisimovienè et al., 2009; Viskelis et al., 2010). On the other hand, our data are in agreement with data of other investigators showing that in other Ribes, Rubus and Vaccinium cultivars or hybrids (Moyer et al., 2002) correlation between anthocyanins or phenolic contents not always exists.

Our results support the theory, that antioxidant effect of berry extracts depends not only on anthocyanins but on stilbenes, ellagitanins, tanins, proanthocyanidins, phenolic acids also (Maatta et al., 2001; Heinonen, 2007; Shipp, Abdel-Ala, 2010). Though antioxidative activity of berry extracts may be related to composition and ratio between different anthocyanins compounds.

\section{Anthocyanin composition in berries of interspecific blackcurrant hybrids}

Anthocyanin content and amount in berries of blackcurrant 'Ben 'Tirran' and interspecific asymmetric hybrids of blackcurrant with currant species depending to other sections was evaluated using HPLC (Table 1). 6-7 Anthocyanins were identified in all the extracts; however 2-5 anthocyanins remained unidentified in each sample. Berry extracts of 'Ben Tirran' and hybrid No. 11-13 (R. nigrum $\times R$. petraeum) had 7 anthocyanins, while 6 anthocyanins were identified in other hybrids berry extracts. Delphinidin 3-O rutinoside was dominant anthocyanin in all studied blackcurrants; it constituted 28-50 percent of total anthocyanin content. Amount of $\mathrm{d} 3 \mathrm{~g}$ was higher in berries of hybrids No. $8((\mathrm{R}$. nigrum $\times \mathrm{R}$. americanum $)$ $\times(R$. nigrum $\times R$. americanum $)$ ) and No. $57(R$. nigrum $\times$ $R$. aureum) than in control cultivar 'Ben Tirran'.

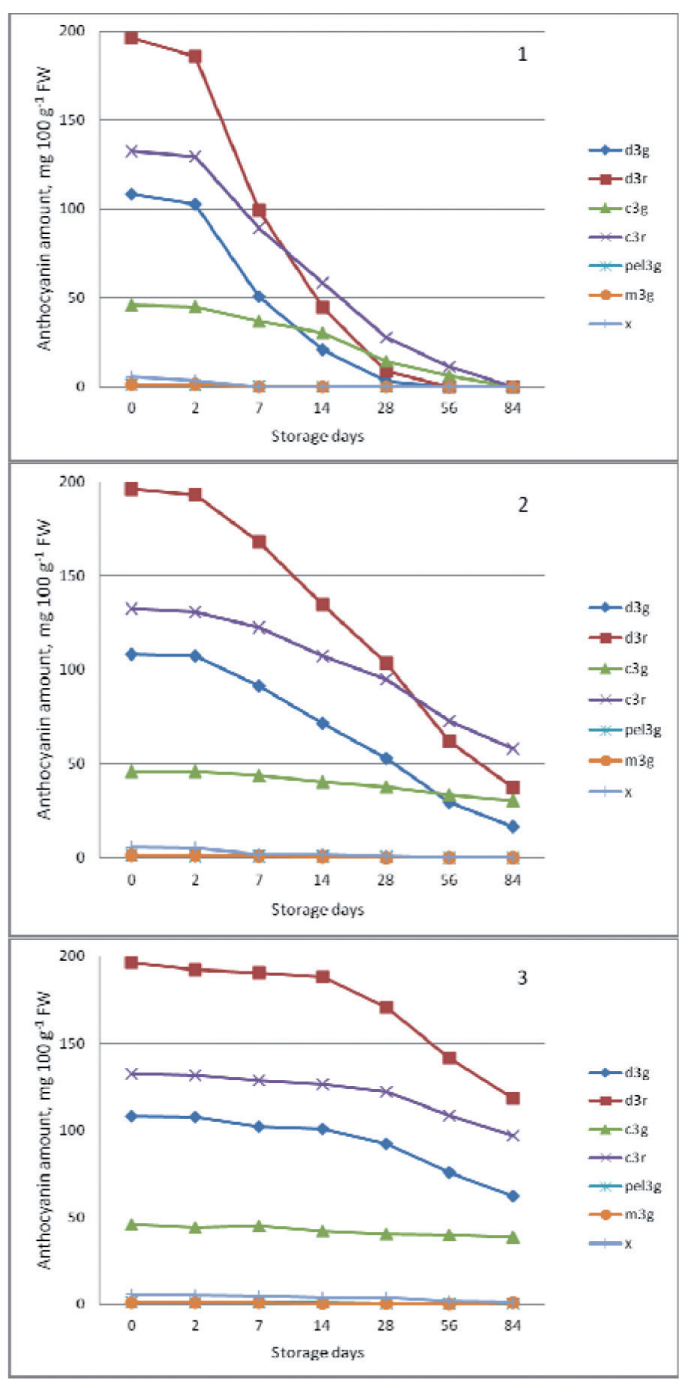

Figure 4. Stability of anthocyanins in berry extracts of interspecific hybrid No. 57 (R. nigrum $\times R$. aureum) during storage at different lighting and temperature conditions.

Storing conditions: $1-+23 \pm 2{ }^{\circ} \mathrm{C}$ with $50-150 \mu \mathrm{mol} \mathrm{m} \mathrm{m}^{-2} \mathrm{~s}^{-1}$ irradiation, $2-+23 \pm 2^{\circ} \mathrm{C}$ in dark, $3-+4 \pm 1^{\circ} \mathrm{C}$ in dark. d $3 \mathrm{~g}-$ delphinidin 3-O-glucoside, $\mathrm{d} 3 \mathrm{r}-$ delphinidin 3-O-rutinoside, c3g - cyanidin 3-O-glucoside, c3r - cyanidin 3-O-rutinoside, pel3g - pelargonidin 3-O-glucoside, $\mathrm{m3g}$ - malvidin 3-O-glucoside, $\mathrm{x}$ - unidentified anthocyanins. 
Amount of cyanidin-3-O glucoside, which is stable anthocyanin, was 1.7-3.3 times higher in berries of all hybrids than in berries of blackcurrant 'Ben Tirran'. C3g content in berries of hybrids No. 57 and No. 11-13 was significantly larger than in berries of 'Ben Tirran'. Similar c3r amount was established in berry extracts of hybrids No. $6((\mathrm{R}$. nigrum $\times \mathrm{R}$. americanum $) \times[(\mathrm{R}$. nigrum $\times \mathrm{R}$. aureum $) \times R$. uva-crispa]), No. 8 and blackcurrant 'Ben Tirran', but was higher in No. 11-13 and No. 57. Malvidin-3-O amount ranged from 1.39 to $5.25 \mathrm{mg} 100 \mathrm{~g}^{-1}$ FW in all studied berries, while peonidin-3-O glucoside was found in 'Ben Tirran' and peonidin-3-O rutinoside in hybrid No. 11-13 berries only. The largest quantity of unidentified anthocyanins was established in berries of 'Ben Tirran' $24.92 \mathrm{mg} 100 \mathrm{~g}^{-1} \mathrm{FW}$ (5.6 percent of total anthocyanins), while in berries of interspecific hybrids amount of unidentified anthocyanins was lower 3.77$16.22 \mathrm{mg} 100 \mathrm{~g}^{-1} \mathrm{FW}$ (1.0-3.8 percent).

\section{Evaluation of anthocyanin stability in berry extracts}

In order to select perspective interspecific currant hybrids with high amount of stable anthocyanins it is important to evaluate stability of individual anthocyanins. Stability of anthocyanins in berry extracts of interspecific hybrid No. 57 ( $R$. nigrum $\times R$. aureum) during storage at different lighting and temperature conditions was evaluated (Fig. 4).

Four anthocyanins (d3g, d3r, c3r, c3g) were dominant in berries of interspecific hybrid No.57, they constituted $98.4 \%$ of all anthocyanins. After storage in room temperature in light for 14 days anthocyanin amount decreased, and only 19-23\% of delphinidins remained, while cyanidins were more stable (41-44\% remained). Only $3-4 \%$ of delphinidins and $18-21 \%$ of cyanidins remained non degraded after storage for 28 days, and almost all anthocyanins were degraded after 56 days. Degradation of anthocyanins in the same extracts, stored at room temperature in dark was slower. More than 69\% of cyanidins and $49-53 \%$ of delphinidins remained stable after storage for 28 days, and $40-44 \%$ of cyanidins and $15-19 \%$ of delphinidins were non degraded after storage for 84 days (Fig. 4). Eighty six to ninty two percent of both delphinidins and cyanidins were stable after storage in dark and cold $\left(+4^{\circ} \mathrm{C}\right)$ conditions after 28 days, and after 84 days in these conditions 72 percent of cyanidins and $59 \%$ of delphinidins were non degraded. Other studies present similar anthocyanin stability data (Hellstrom et al., 2013), but they studied total anthocyanin content only, and our study reveals stability of individual anthocyanin in berry extract.

Data on phenols, anthocyanin quantity and composition show that two interspecific hybrids (No. 11-13 and No.57) equal and exceed 'Ben Tirran'. Thus, the new interspecific hybrids may be characterized as possessing a high health benefits.

\section{CONCLUSIONS}

Amount of total phenolic compounds in berries of interspecific hybrids ranged from 530 to $614 \mathrm{mg} 100 \mathrm{~g}^{-1}$ FW, Ribes nigrum 'Ben Tirran' berries accumulated 621 mg $100 \mathrm{~g}^{-1} \mathrm{FW}$. The highest amount of anthocyanins was established in berries of hybrids No. 11-13 (R. nigrum $\times$ R. petraeum) and No. 57 (R. nigrum $\times$ R. aureum),

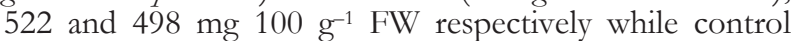
cultivar 'Ben Tirran' berries accumulated $444 \mathrm{mg} 100 \mathrm{~g}^{-1}$ FW of anthocyanins. The highest antioxidative activity was identified in berry extracts of hybrid No. 11-13
$(80 \%)$ and it was higher than antioxidant activity of 'Ben Tirran' (70\%). Andioxidative activity of all tested berry extracts $(70-80 \%)$ was twice higher compared to synthetic antioxidant BHT (39\%). Direct correlation between total anthocyanin or phenolics amount and degree of antioxidative activity was not established. Amount of cyanidin 3-O-glucoside and cyanidin 3-O-rutinoside in berries of hybrids No. 57, No. 11-13 and No. 8 ((R. nigrum $\times R$. americanum $) \times(R$. nigrum $\times R$. americanum $)$ ) was higher than in berries of 'Ben Tirran'. It was established that cyanidins are more stable anthocyanins in all studied storing conditions. Therefore hybrids No. 57 and No. 11-13 are perspective for production of food additives or colorants.

\section{Acknowledegment}

Research was funded by a grant No SVE-01/2011 from the Research Council of Lithuania.

\section{REFERENCES}

Anisimoviene N, Rubinskienè M, Viškelis P, Stackevičienė E, Stanys V, Šikšnianas T, Jankovska E, Sasnauskas A (2009) Anthocyanins in currants, cherries, blueberries, and antioxidative activity of berry extracts. Zemdirbyste-Agriculture 96: 158-167.

Arnnok P, Ruangviriyachai C, Malachai R, Techawongstien S, Chanthai S (2012) Determination of total phenolics and anthocyanin contents in the pericarp of hot chilli pepper (Capsinum annuum L.). Intern. Food Research Journal 19: 235-243.

Blando F, Gerardi C, Nicoletti I (2004) Sour cherry (Prunus cerasus L.) anthocyanins as ingredients for functional food. J. of Biomedicine and Biotechnology 5: 253-258.

Borges G, Degeneve A, Mullen W, Crozier A (2010) Identification of flavonoid and phenolic antioxidants in black currants, blueberries, raspberries, red currants, and cranberries. J. Agric. Food Chemistry 58: 3901-3909.

Bunea A, Rugina DO, Pintea AM, Sconta Z, Bunea CI, Socaciu C (2011) Comparative polyphenolic content and antioxidative activities of some wild and cultivated blueberries from Romania. Notulae Botanicae Horti Agrobotanici Cluj-Napoca 39: 70-76.

Denev PN, Kratchanov CG, Ciz M, Lojek A, Kratchanova MG (2012) Bioavilability and antioxidant activity of black chokeberry (Aronia melonocarpa) polyphenols: in vitro and in vivo evidences and possible mechanism of action: A review. Comprehensive Reviews in Food Science and Food Safety 11: 471-489.

Djordjević B, Savikin K, Zdunić G, Janković T, Vulić T, Oparnica C, Radivojević D (2010) Biochemical properties of red currant varieties in relation to storage. Materiae Vegetabiles 65: 326-332.

Durst RW, Wrolstad R (2001) Separation and characterization of anthocyanins by HPLC. Current Protocols in Food Analytical Chemistry F1.3.1-F1.3.13.

Guerrero J, Ciampi LP, Castila AC, Medel FS, Schalchli HS, Hormazabal EU, Bensch ET, Alberdi ML (2010) Antioxidant capacity, anthocyanins, and total phenols of wild and cultivated berries in Chile. Chilean I Agricultural Res 74: 537-544.

Hassanpour H, Hamidoghli Y, Hajilo J, Adlipour M (2011) Antioxidant capacity and phytochemical properties of cornelian cherry (Cornus mas L.) genotypes in Iran. Scientia Horticulturae 129: 459-463.

He J, Giusti MM (2010) Anthocyanins: natural colorants with health-promoting properties. Annual Review Food Sci Technol 1: 16387.

Heinonen M (2007) Antioxidant activity and antimicrobial effect of berry phenolics - a Finnish perspective. Mol Nutrition Food Res 51: 684-691.

Hellström J, Hietaranta T, Kartu S, Mattila P, Tiirkka T, Vetelainen M (2010) High variability in anthocyanin contents between different blackcurrant varieties. NJF Report. 6: 116-118.

Hellstrom J, Mattila P, Karjalainen R (2013) Stability of anthocyanins in berry juices stored at different temperatures. I Food Comp Anal 31: $12-19$.

Horbowicz M, Kosson R, Grzesiuk A, Dębski H (2008) Anthocyanins in fruit and vegetables - their occurrence, analysis and role in human nutrition. Vegetable Crops Res Bull 68: 5-22.

Javanmardi J, Stushnoff C, Locke E, Vivanco JM (2003) Antioxidant activity and total phenolic content of Iranian Ocimum accessions. Food Chemistry 83: 547-550.

Liegiūtė S, Majienė D, Trumbeckaite S, Liobikas J, Bendokas V, Stanys V, Kopustinskienè D M, Šikšnianas T, Anisimovienė N (2009) Anthocyanin composition and antimicrobial activity of sour cherry (Prunus cerasus L.) fruit extracts. Zemdirbyste-Agriculture 96: 141-148. 
Liobikas J, Trumbeckaite S, Bendokas V, Baniulis D, Majiené D, Kopustinskienè DM, Šikšnianas T, Anisimovienė N (2009). Proapoptotic effect of black currant berry extracts on rat heart mitochondria. Zemdirbyste-Agriculture 96: 149-157.

Lugasi A, Hovari J, Kadar G, Denes F (2011) Phenolics in raspberry and currant cultivars grown in Hungary. Acta Alimentaria 40: 52-64.

Maatta K, Kamal-Eldin A, Törrönen R (2001) Phenolics compounds in berries of black, red, green and white currants (Ribes sp.). Antioxidant Redox Signal 3: 981-993.

Moyer RA, Hummer KE, Finn CE, Frei B, Wrolstad RE (2002) Anthocyanins, phenolic, and antioxidant capacity in diverse small fruits: Vaccinium, Rubrus and Ribes. J Agric Food Chem 50: 519-525.

Nour V, Trandafir I, Ionica ME (2011) Ascorbic acid, anthocyanins, organic acids and mineral content of some black and red currants. Fruits 66: 353-362.

Oancea S, Oprean L (2011) Anthocyanins, from biosynthesis in plants to human health benefits. Acta Uninversitatis Cibiniensis. Series E: Food Technology 15: 3-15.

Pantelidis GE, Vasilakakis M, Manganaris GA, Diamantidis G (2007) Antioxidant capacity, phenol, anthocyanin and ascorbic acid contents in raspberries, blackberries, red currants, gooseberries and Cornelian cherries. Food Chemistry 102: 777-783.

Pascual-Teresa S, Sanchez-Ballesta MT (2008) Anthocyanins: from plant to health. Biochemistry Reviews 7: 281-299.

Pinto MDS, Kwon Y-I, Apostolidis E, Lajolo FM, Genovese MI, Shetty K (2010) Evolution of red currants (Ribes rubrum L.), black currants (Ribes nigrum L.), red and green gooseberries (Ribes uva-crispa) for potential management of type 2 diabetes and hypertension using in vitro models. J Food Biochem 34: 639-660.
Pourmorad F, Hosseinimehr S, Shahabimajd JN (2006) Antioxidant activity, phenol and flavonoid contents of some selected Iranian medicinal plants. African J Biotechnol 5: 1142-1145.

Rubinskiene M, Jasutiene I, Venskutonis PR, Viskelis P (2005) HPLC determination of the composition and stability of blackcurrant anthocyanins. J Chromatographic Scie 43: 478-482.

Sánchez-Moreno C (2002) Methods used to evaluate the free radical scavenging activity in foods and biological systems. Food Science Technology Int 8: 121-137.

Shipp J, Abdel-Aal El-SM (2010) Food application and physiological effects of anthocyanins as functional food ingredients. The Open Food Science Journal 4: 7-22.

Slimestad R, Solheim H (2002) Anthocyanins from black currants (Ribes nigrum L.). I Agric Food Chem 50: 3228-3231.

Slinkard K, Singleton VL (1977) Total phenol analysis: automation and comparison with manual methods. Am J Enol Vitic 28: 49-55.

Tsuda T (2012) Dietary anthocyanin-rich plants: Biochemical basis and recent progress in health benefits studies. Mol Nutr Food Res 56: 159-170.

Viskelis P, Anisimovienė N, Rubinskienè M, Jankovska E, Sasnauskas A (2010) Physical properties, anthocyanins and antioxidant activity of blackcurrant berries of different maturities. J Food Agric Environment 8: 159-162.

Wrolstad RE, Durst RW, Lee J (2005) Tracking colour and pigment changes in anthocyanin products. Trends Food Sci Technol 16: 423428 . 